\title{
Avanafil for erectile dysfunction in elderly and younger adults: differential pharmacology and clinical utility
}

This article was published in the following Dove Press journal:

Therapeutics and Clinical Risk Management

27 August 2014

Number of times this article has been viewed

\author{
Eric G Katz' \\ Ronny BW Tan² \\ Daniel Rittenberg' \\ Wayne J Hellstrom ${ }^{3}$ \\ 'Tulane University School of \\ Medicine, New Orleans, LA, USA; \\ ${ }^{2}$ Department of Urology, Tan Tock \\ Seng Hospital, Singapore; '3ection of \\ Andrology, Department of Urology, \\ Tulane University School of Medicine, \\ New Orleans, LA, USA
}

\begin{abstract}
The treatment modalities of erectile dysfunction range from oral pharmacotherapy to intracavernosal injections, intraurethral pellets, vacuum erectile devices, and the surgical option of penile prosthesis insertion. Oral phosphodiesterase 5 inhibitors still remain the preferred treatment for patients since they are the least invasive, not to mention that they can be prescribed by non-urologists. Due to these factors, there has been development of newer drugs with fewer side effects. This is a review of the second generation phosphodiesterase 5 inhibitor, avanafil, looking into its pharmacology as well as its clinical utility. Avanafil's faster onset and shorter duration of action has made it preferred as compared to other PDE5 inhibitors for patients with multiple comorbidities.
\end{abstract}

Keywords: phosphodiesterase 5 inhibitors, impotence, sildenafil, sexual dysfunction, nitric oxide

\section{Introduction}

Erectile dysfunction (ED), defined as the inability to achieve or maintain an erection sufficient for satisfactory sexual performance, is common. ${ }^{1}$ Clinicians face a complex set of questions, as ED has physical, psychological, and emotional implications. Numerous studies have elucidated the psychosocial ramifications of ED, suggesting profound psychological distress that can impair a patient's quality of life. ${ }^{2,3}$ Specifically, afflicted men experience a depreciated sense of self-worth, impaired social functioning, and marital problems. ${ }^{2,3}$ It is noteworthy that ED is a widespread complaint, affecting 18 million men in the USA and 150 million men worldwide., ${ }^{4,5}$ These figures are expected to double by 2025 due to the aging population and increasing frequency of related health problems. ${ }^{4}$

The first line of medical therapy for ED is phosphodiesterase (PDE) 5 inhibitors. ${ }^{1,6,7}$ These drugs augment the natural physiologic process of tumescence. ${ }^{6,8}$ During penile erection, nitric oxide stimulates cyclic guanosine monophosphate (cGMP) production in vascular smooth muscle cells of the corpus cavernosum. ${ }^{6,9}$ cGMP acts through a series of intracellular pathways to lower the intracellular level of calcium that, in turn, causes cavernosal smooth muscle relaxation and penile arterial vessel dilation. ${ }^{6,9}$

PDE5 is the primary enzyme responsible for the catabolism of cGMP in these cells, thereby mediating the detumescent signal. ${ }^{6,8,10,11}$ The discovery of oral PDE5inhibitor drugs that can inhibit this enzyme has transformed the therapeutic options available to this patient population. ${ }^{6}$ PDE5 inhibitors are structural analogs of cGMP that competitively bind to the catalytic site of PDE5 and inhibit its hydrolytic activity. ${ }^{6,8,10,11}$ Elevated cGMP levels increase penile blood flow and amplify the neurologic signal for erection. ${ }^{6,8,10,11}$
Correspondence: Wayne J Hellstrom

Tulane University Health Sciences

Center, Department of Urology,

I430 Tulane Ave SL-42,

New Orleans, LA, 701 12, USA

Tel +l 5049885372

Fax + I 5049885059

Email whellst@tulane.edu submit your manuscript | www.dovepress.com

Dovepress

http://dx.doi.org// 0.2147/TCRM.S57610
Therapeutics and Clinical Risk Management 20I4:I0 70I-7II 
PDE5 inhibitors, which include sildenafil, vardenafil, tadalafil, and avanafil, have been widely accepted as first-line therapy for various forms of ED..$^{1,6-8,12}$ This includes organic ED, psychogenic ED, and mixed ED, as well as patients with concurrent diabetes, cardiovascular disease, and a history of urologic pelvic surgery. ${ }^{6,8,12}$ Overall, efficacy rates for PDE5 inhibitors are reported to be as high as $60 \%-80 \% .^{1,6-8,12}$ Commonly reported adverse effects include headache, flushing, dyspepsia, visual disturbances, and myalgia. ${ }^{6,8,10,11}$ These side effects are attributed to the current PDE5 inhibitors' effect on other PDE isoenzymes, an element that is addressed in this review. $6,8,10,11$

It is important to note that there still remains a substantial subset - approximately 30\% - of patients who fail current PDE5 inhibitor therapy. ${ }^{1,6-8,12}$ This may be due to lack of physiologic response, intolerable adverse effects, or a combination of the two. ${ }^{6,10}$ Consequently, researchers are attempting to modulate current PDE5 inhibitors to create safer and more effective options. There are several drugs in development, including JNJ-10280205, JNJ-10287069, lodenafil, mirodenafil, SLx-2101, and udenafil. ${ }^{10-14}$ Mirodenafil and udenafil are only approved for use in Korea. ${ }^{12,13,15}$ The remainder of the drugs are still in clinical testing. ${ }^{12,13,15}$

This review focuses on avanafil, a highly selective second-generation oral PDE5 inhibitor originally developed by Mitsubishi Tanabe Pharma Corporation (Yokohoma, Japan) under the substance code TA-1790 and purchased by Vivus (Mountain View, CA, USA), which has completed Phase III clinical trials, and was recently approved by the US Food and Drug Administration. ${ }^{10,13,15-17}$ Studies have demonstrated that avanafil offers increased selectivity for the PDE5 isoenzyme, which may be important in reducing the incidence of adverse effects. ${ }^{10,13,15,17}$ Furthermore, avanafil has a faster onset of action, shorter duration of action, and fewer drug interactions than current PDE5 inhibitor options. ${ }^{10,13,15,17}$ With this drug profile, avanafil appears to be a favorable option for ED patients.

\section{Pharmacological profile of avanafil}

Avanafil (4-[(3-chloro-4-methoxybenzyl) amino]-2-[2-(hydroxymethyl)-1 -pyrrolidinyl]$N$-(2-pyrimidinylmethyl)-5-pyrimidinecarboxamide; (S)-2-(2-hydroxymethyl-1-pyrrolidinyl)-4-(3-chloro-4methoxybenzylamino)-5-[(2-pyrimidinylmethyl)carbamoyl] pyrimidine) is a pyrimidine derivative that has a molecular weight of 483.95 and exists as a single enantiomer with S stereochemistry. ${ }^{10,11,17}$ It presents as a white crystalline powder in its pure form, which is minimally soluble in water and moderately soluble in organic solvent. Solubility testing at various $\mathrm{pH}$ values revealed increased solubility in acidic buffers (approximately $\mathrm{pH} 4$ ) and decreased solubility in neutral and alkaline buffers. ${ }^{11,17}$

Avanafil is a potent inhibitor of PDE5, as demonstrated by its half-maximal inhibitory concentration of $4.3-5.2 \mathrm{nM} .^{18} \mathrm{It}$ reaches its maximal concentration in plasma $\left(\mathrm{T}_{\max }\right) 30-45$ minutes after dosing, indicating rapid diffusion into the bloodstream when administered orally. ${ }^{18,19}$ This stands in contrast to the existing PDE5 inhibitors, sildenafil, vardenafil, and tadalafil, with $\mathrm{T}_{\max }$ values of 60 minutes, 60 minutes, and 120 minutes, respectively. ${ }^{19-21}$ Thus, in the fasting state, avanafil appears to offer a faster onset of action than current therapies (Table 1).

Absorption of avanafil from the gastrointestinal tract is affected by coadministration of food. When avanafil is taken with a high-fat meal, $\mathrm{T}_{\max }$ is delayed 1.12-1.25 hours, compared to 1 hour for sildenafil and vardenafil. ${ }^{13,22-24}$ Tadalafil is unaffected by coadministration of a high-fat meal. ${ }^{21,25}$

Another clinical difference between these drugs is duration of action. Avanafil has a plasma half-life $\left(\mathrm{T}_{1 / 2}\right)$ of 3-5 hours and a maximal duration of action of 6 hours. ${ }^{13,18}$ Sildenafil has a similar $\mathrm{T}_{1 / 2}$ of approximately 4 hours, but efficacy can last up to 12 hours. ${ }^{19,26,27}$ Vardenafil shares similar pharmacokinetic properties as sildenafil. It has a $\mathrm{T}_{1 / 2}$ of 4-5 hours and its efficacy can last 12 hours. ${ }^{13,20}$ The main exception within this group is tadalafil. Tadalafil offers a longer duration of action: its $T_{1 / 2}$ is 17.5 hours and efficacy is maintained for up to 36 hours. ${ }^{21,27,28}$ Avanafil's pharmacokinetic profile, particularly its shorter period of efficacy, may offer a unique option to patients with ED.

\section{Pharmacodynamics}

There are several PDE isoenzymes distributed in tissues throughout the body. The PDE5 inhibitors used to treat ED specifically aim to inhibit the PDE enzyme within the smooth muscle of the corpus cavernosum. However, these drugs can also sometimes exert activity against PDE isoenzymes in other tissues, leading to adverse events (AEs) (Table 2). The selectivity of any of these drugs for the various PDE isoenzymes defines its side effect profile (Table 3). ${ }^{29-31}$

PDE6 is located in the retina and is involved in signal transduction in the photoresponse of the eye. ${ }^{29-31}$ PDE5 inhibitors that cross-react with PDE6 have been associated with visual disturbances, specifically transient cyanopsia (perception of a bluish tinge to vision), sensitivity to light, and blurred vision. ${ }^{29-32}$ These effects are typically mild and transient, and occur at the $\mathrm{T}_{\max }$ of the particular drug. Within this group, sildenafil has been most associated with 
Table I Summary of pharmacokinetics of avanafil, sildenafil, vardenafil, and tadalafil

\begin{tabular}{lllll}
\hline Parameter & Avanafil & Sildenafil & Vardenafil & Tadalafil \\
\hline $\mathrm{T}_{\max }(\mathrm{min})$ & $30-45$ & 60 & 60 & 120 \\
Onset of action & 15 & $30-60$ & $15-30$ & $15-45$ \\
Delay with high-fat meal $(\mathrm{min})$ & $67-75$ & 60 & 60 & 0 \\
$\mathrm{~T}_{1 / 2}(\mathrm{hr})$ & $3-5$ & 4 & $4-5$ & 17.5 \\
Duration of action $(\mathrm{hr})$ & 6 & 12 & 12 & 36 \\
Metabolism & Hepatic (CYP3A4) & Hepatic (CYP3A4) & Hepatic (CYP3A4) & Hepatic (CYP3A4) \\
Mode of excretion & Feces (62\%), urine (21\%) & Feces (80\%), urine (I3\%) & Feces (91\%-95\%), urine (2\%-6\%) & Feces (6I\%), urine (36\%) \\
\hline
\end{tabular}

Abbreviations: min, minutes; hr, hours; $\mathrm{T}_{1 / 2}$, plasma half-life; $\mathrm{T}_{\max }$, time to maximum concentration; CYP, cytochrome $\mathrm{P}$.

Table 2 Summary of the clinically relevant PDE isoenzymes

\begin{tabular}{llll}
\hline PDE isoenzyme & Tissue expression & Main function & Suggested associated AEs \\
\hline PDEI & $\begin{array}{l}\text { Brain, heart, vascular smooth muscle, } \\
\text { testis, immune system } \\
\text { Vascular smooth muscle (corpus } \\
\text { cavernosum, lung), platelets, heart, brain }\end{array}$ & $\begin{array}{l}\text { Neuronal signaling, vascular smooth } \\
\text { muscle proliferation and contraction } \\
\text { Vascular smooth muscle contraction }\end{array}$ & $\begin{array}{l}\text { Hemodynamic effects, } \\
\text { interaction with nitroglycerin }\end{array}$ \\
RDE5 & Retina & Visual phototransduction & Cyanopsia, sensitivity to light, \\
PDE6 & Skeletal muscle, prostate, testis, liver, & Unknown, but possible role in & Back pain, myalgia \\
PDEII & heart, pituitary & sperm development and function & \\
\hline
\end{tabular}

Abbreviations: AEs, adverse events; PDE, phosphodiesterase.

Table 3 Potency and selectivity (fold difference versus PDE5) of avanafil, sildenafil, vardenafil, and tadalafil for clinically relevant PDE isoenzymes

\begin{tabular}{|c|c|c|c|c|}
\hline Parameter & Avanafil & Sildenafil & Vardenafil & Tadalafil \\
\hline Mean $\mathrm{IC}_{50}$ for PDE5 (nM) & 5.2 & 1.6 & 0.1 & 4.0 \\
\hline Selectivity for PDEI versus PDE5 & $>10,000$-fold & 375-fold & I,000-fold & $>10,000$-fold \\
\hline Selectivity for PDE6 versus PDE5 & $|2|$-fold & I6-fold & 2I-fold & 550 -fold \\
\hline Selectivity for PDEII versus PDE5 & $>19,000$-fold & 4,875 -fold & 5,950 -fold & 25-fold \\
\hline
\end{tabular}

Abbreviations: $\mathrm{IC}_{50}$, half-maximal inhibitory concentration; PDE, phosphodiesterase.

Table 4 Phase III clinical trials overview

\begin{tabular}{|c|c|c|c|c|c|c|c|c|c|}
\hline \multirow[t]{2}{*}{ Trial } & \multirow[t]{2}{*}{ Population } & \multirow{2}{*}{$\begin{array}{l}\text { Patient } \\
\text { number }\end{array}$} & \multirow{2}{*}{$\begin{array}{l}\text { Treatment } \\
\text { duration }\end{array}$} & \multirow{2}{*}{$\begin{array}{l}\text { Dosage } \\
\text { (mg) }\end{array}$} & \multicolumn{5}{|c|}{ Results } \\
\hline & & & & & IIEF & SEP2 & SEP3 & AEs & $\begin{array}{l}\text { Discontinuation } \\
\text { due to AEs }\end{array}$ \\
\hline \multirow{5}{*}{$\begin{array}{l}\text { Goldstein et } \mathrm{al}^{45} \\
\text { REVIVE (TA-30I) }\end{array}$} & General (excludes & 646 & 12 weeks & Placebo & 2.9 & $7.0 \%$ & $14.0 \%$ & $26.1 \%$ & $3.1 \%$ \\
\hline & diabetes) & & & & & & & & \\
\hline & & & & Avanafil 50 & $5.5^{*}$ & 19\%* & $28.0 \% *$ & $32.5 \%$ & $1.9 \%$ \\
\hline & & & & Avanafil 100 & $8.3 * * *$ & $27.0 \% * * *$ & $43.0 \% * * *$ & $42.2 \%$ & $3.1 \%$ \\
\hline & & & & Avanafil 200 & $9.4 * * *$ & $29.0 \% * * *$ & $45.0 \% * * *$ & $38.9 \%$ & $2.5 \%$ \\
\hline \multirow{4}{*}{$\begin{array}{l}\text { Goldstein et } \text { al }^{46} \\
\text { REVIVE-D (TA-302) }\end{array}$} & Diabetes & 390 & 12 weeks & Placebo & 1.8 & $7.5 \%$ & $13.6 \% * *$ & $23.8 \%$ & $0.0 \%$ \\
\hline & & & & & & & & & \\
\hline & & & & Avanafil 100 & $4.5^{* *}$ & $21.5 \% * *$ & $28.7 \% * *$ & $35.4 \%$ & $0.0 \%$ \\
\hline & & & & Avanafil 200 & $5.4 * *$ & $25.9 \% * *$ & $34.0 \% * *$ & $32.1 \%$ & $0.8 \%$ \\
\hline \multirow{4}{*}{$\begin{array}{l}\text { Mulhall et al }{ }^{47} \\
\text { REVIVE-RP (TA-303) }\end{array}$} & Post-radical & 298 & 12 weeks & Placebo & 0.1 & $0.0 \%$ & $5.0 \%$ & $23.0 \%$ & $0.01 \%$ \\
\hline & prostatectomy & & & & & & & & \\
\hline & & & & Avanafil 100 & $3.6 * *$ & $15.0 \% * *$ & | $8.0 \% * *$ & $38.4 \%$ & $0.02 \%$ \\
\hline & & & & Avanafil 200 & $5.2 * *$ & $21.0 \% * *$ & $21.0 \%$ & $45.5 \%$ & $0.02 \%$ \\
\hline \multirow{4}{*}{$\begin{array}{l}\text { Belkoff et al }{ }^{48} \\
\text { REVIVE-S (TA-3 I4) }\end{array}$} & Open label & 712 & 52 weeks & Avanafil 100 & 8.6 & $39.2 \%$ & $54.4 \%$ & $19.0 \%$ & $1.8 \%$ \\
\hline & & & & only & & & & & \\
\hline & & & & Avanafil & 10.8 & $36.4 \%$ & $54.9 \%$ & $35.6 \%$ & $1.2 \%$ \\
\hline & & & & $100 / 200$ & & & & & \\
\hline
\end{tabular}

Notes: $* P<0.005$ versus placebo; $* * P<0.00$ I versus placebo; $* * * P<0.000$ I versus placebo.

Abbreviations: AEs, adverse events; IIEF, International Index of Erectile Function; REVIVE, Research Evaluating an Investigational Medication for Erectile Dysfunction; REVIVE-D, Research Evaluating an Investigational Medication for Erectile Dysfunction with Diabetes; REVIVE-RP, Research Evaluating an Investigational Medication for Erectile Dysfunction with Radical Prostatectomy; REVIVE-S, Research Evaluating an Investigational Medication for Erectile Dysfunction Safety Trial; SEP2, Sexual Encounter Profile question two: "Were you able to insert your penis into your partner's vagina?"; SEP3, Sexual Encounter Profile question three: "Did your erection last long enough for you to complete intercourse with ejaculation?". 
visual AEs, occurring in 5\% of patients receiving sildenafil compared to $<1 \%$ of patients receiving placebo. These effects were dose-dependent, and patients on higher doses of sildenafil, such as 100 and $200 \mathrm{mg}$, have reported an increased incidence of visual AEs. ${ }^{32-34}$ Vardenafil and tadalafil have fewer reported visual AEs, with incidences of $2 \%$ and $0.1 \%$, respectively. ${ }^{34}$

An in vitro study demonstrated the relative selectivity of PDE5 inhibitors against various PDE isoenzymes. ${ }^{31,35}$ For PDE6, avanafil had greater selectivity (121-fold) than sildenafil (16-fold) and vardenafil (21-fold), but less selectivity than tadalafil (550-fold). A study of anesthetized dogs reflected these findings. ${ }^{36}$ As assessed by electroretinogram (ERG), avanafil had less effect on retinal function than sildenafil. Intraduodenal doses of avanafil (10 and $30 \mathrm{mg} / \mathrm{kg}$ ) did not affect the ERG waveform. Conversely, administration of sildenafil affected the ERG waveform, causing a delay in the peak of the ERG positive wave. This effect can be explained by increased inhibition of PDE6 by sildenafil, thereby slowing phototransduction in the retina. Hence, this in vivo study confirms avanafil's superior selectivity for PDE6 when compared with sildenafil.

PDE1 is involved in vascular smooth muscle contraction throughout the body. ${ }^{29-31,37}$ The PDE5 inhibitors that crossreact with PDE1, particularly sildenafil, have been associated with cardiovascular effects. These include hypotensive events, especially with coadministration of nitrates, which are used as a vasodilating treatment medication for unrelenting angina pectoris. For this reason, current PDE5 inhibitors are contraindicated for concurrent use with nitrates. PDE5 inhibitors can also potentiate the hypotensive effects of alpha-blockers, causing symptomatic hypotension. The coadministration of currently approved PDE5 inhibitors with alpha-blockers should be administered with caution. ${ }^{19-21}$

Given the cardiovascular effects of current PDE5 inhibitors, it is important to investigate suitable options for ED patients with coexistent cardiovascular conditions that may necessitate use of blood-pressure lowering medications. Among current PDE5 inhibitors, tadalafil has the highest selectivity for PDE1 ( $<10,000$-fold), while vardenafil (1,000-fold) and sildenafil (375-fold) have significantly lower selectivities for this enzyme. Avanafil has comparable selectivity to tadalafil for PDE1 (10,200-fold). ${ }^{31,35}$

The hemodynamic effects of avanafil were compared with sildenafil in a study of anesthetized dogs. ${ }^{36}$ Intravenous administration of either drug alone significantly decreased systemic blood pressure and total peripheral resistance. However, whereas sildenafil affected heart rate and resistance of the common carotid and vertebral arteries, avanafil had no effect on these vascular parameters. This study then investigated synergistic effects of either sildenafil or avanafil with the coadministration of nitroglycerin (NTG). Though both drugs were shown to potentiate NTG-induced hypotension, avanafil's potentiating effects were weaker and shorter in duration. These results correlate with the in vitro study indicating avanafil's superior selectivity for PDE1. ${ }^{35}$ Avanafil was also shown to potentiate sodium nitroprussideinduced inhibition of platelet aggregation to a lesser extent than sildenafil. ${ }^{11,17}$ Avanafil appears to provide a favorable pharmacodynamic profile, particularly for patients with cardiovascular compromise, as it has been shown to have a weaker and briefer interaction with organic nitrates.

Another PDE isoenzyme that has been studied for its role in PDE5-inhibitor side effects is PDE11, which is located in skeletal muscle as well as the prostate and testes. ${ }^{31,35}$ Tadalafil is far less selective (25-fold) for PDE11 than the other approved PDE5 inhibitors. Though this crossreactivity does not appear to impact testicular function or spermatogenesis, it may affect skeletal muscle. ${ }^{38}$ Back pain and myalgia are reported in $5 \%$ and $2 \%$ of patients taking tadalafil, respectively. ${ }^{13}$ Avanafil showed favorable selectivity for PDE11 (>19,000-fold) compared to the other three current PDE5 inhibitors on the market. ${ }^{31,35}$

\section{Pharmacokinetics and metabolism}

Comparison of avanafil and sildenafil in anesthetized dogs revealed quicker onset of action for avanafil. ${ }^{35}$ Time to peak response for avanafil and sildenafil was 10 and 30 minutes, respectively. This study also demonstrated comparable efficacy of these two PDE5 inhibitors. At maximal drug concentrations, avanafil and sildenafil potentiated penile tumescence by $325 \%$ and $304 \%$ (intravenous), and $415 \%$ and $358 \%$ (intra-duodenal), respectively. The $200 \%$ effective doses of avanafil and sildenafil on tumescence were $37.5 \mu \mathrm{g} / \mathrm{kg}$ and $34.6 \mu \mathrm{g} / \mathrm{kg}$ after intravenous injection, respectively. Both drugs produced dose-dependent changes in intracavernosal pressure following pelvic nerve stimulation. The efficacy of avanafil in vivo was also demonstrated in a study of type 2 diabetic rats. ${ }^{39}$ Intracavernosal injection of avanafil partially restored diminished erectile responses in diabetic rats.

Avanafil is cleared by hepatic metabolism, primarily by the cytochrome P450 isoenzyme CYP3A4 and, to a smaller extent, by the CYP2C isoenzyme. Its two major metabolites are M4 and M16. The plasma concentration of M4 is 23\% of that of the parent compound. It has an in vitro inhibitory potency for PDE5 that is $18 \%$ of that of the parent compound 
and it accounts for $4 \%$ of total pharmacologic activity. The plasma concentration of the M16 metabolite is 29\% of that of the parent compound; it does not exert any pharmacologic activity against PDE5. ${ }^{22}$ Avanafil and its metabolites are primarily excreted in the feces after oral and intravenous dosing. In vivo studies of rats and dogs demonstrated nearly total elimination of avanafil and its metabolites from plasma 96 hours after intravenous administration. ${ }^{11}$

\section{Clinical efficacy, safety, and tolerability Phase I studies}

A Phase I study of 32 male subjects investigated the pharmacokinetics and tolerability of avanafil. ${ }^{40}$ Avanafil had a mean $\mathrm{T}_{\text {max }}$ of 20-31 minutes, signifying rapid absorption from the gastrointestinal tract. Measurement of drug elimination yielded variable results, with mean $T_{1 / 2}$ of 5.36-10.66 hours. Importantly, this study demonstrated that avanafil did not accumulate to a significant extent in the plasma of patients after 7 days of receiving the highest daily dose (200 mg). Avanafil exhibited linear pharmacokinetic properties at all administered doses $(50,100$, and $200 \mathrm{mg})$, as measurements of area under the curve and maximal concentration in plasma were dose-dependent.

AEs occurred in $80 \%$ of patients receiving avanafil, compared to $67 \%$ of those receiving placebo. The most common AEs were flushing, headache, and dizziness. All AEs were mild; none required intervention. Furthermore, patients did not experience any clinically relevant changes in vital signs, electrocardiogram (EKG), or color discrimination. This study was limited by two deficiencies. First, the subjects were young and healthy (mean age of 23.4 years), which may not match up with the age and health status of patients using avanafil for ED. Second, the sample size was small, which limits extrapolation to a larger population.

The interaction of avanafil with organic nitrates was compared with sildenafil in a Phase I study of 106 healthy males. ${ }^{41}$ Subjects received an NTG tablet in varying increments following prior dosing with either avanafil or sildenafil. Hemodynamic effects were assessed by systolic blood pressure, diastolic blood pressure, and heart rate. Avanafil documented superiority to sildenafil in several parameters. Compared with sildenafil, avanafil resulted in smaller changes in blood pressure and heart rate when administered with NTG. Avanafil also caused fewer clinically significant reductions in systolic blood pressure $(\geq 30 \mathrm{mmHg}$ ) than sildenafil (15\% versus 29\%). However, the incidence of symptomatic hypotensive AEs was comparable with avanafil or sildenafil use: $27 \%$ and $29 \%$, respectively. Moreover, avanafil appeared inferior to sildenafil in one area. Four subjects on avanafil experienced syncope, compared to only one patient on sildenafil. Despite the incidence of syncopal events, it appears as though avanafil has a smaller potentiating effect on hemodynamics with concomitant use of NTG when compared to sildenafil. This supports the increased specificity of avanafil for PDE5 over other PDE isoenzymes, particularly PDE1. ${ }^{31,35,36}$

The duration of the interaction between these PDE5 inhibitors and NTG was elucidated by Swearingen et al. ${ }^{41}$ Both avanafil and sildenafil had maximal synergistic effects on hemodynamics when NTG was administered 30 minutes after dosing of the PDE5 inhibitor. Hemodynamic effects of both drugs declined after that time point. Significantly, whereas avanafil had no significant effect on blood pressure and heart rate if administered 8 hours after NTG, sildenafil maintained an effect up to 12 hours. Avanafil has a documented quick onset of action and short duration of effect, and these properties may result in briefer interactions with drugs with similar mechanisms, such as organic nitrates.

\section{Phase II studies}

A Phase II single-blind multi-centered randomized crossover study evaluated the safety and efficacy of avanafil compared to sildenafil and placebo. ${ }^{42}$ The study group included 83 males aged 35-70 years, all with a subjective complaint of mild to moderate ED of $\geq 6$ months' duration. Subjects were randomized to receive the following treatments in random sequence: placebo; sildenafil $50 \mathrm{mg}$; and either avanafil $50 \mathrm{mg}$, avanafil $100 \mathrm{mg}$, or avanafil $200 \mathrm{mg}$. At each appointment, patients were given visual sexual stimulation (VSS) to watch during discrete 20 -minute periods beginning 20 minutes before dosing and concluding 120 minutes after dosing. Erectile function was assessed by measurement of penile rigidity using a RigiScan (Dacomed Corporation, Minneapolis, MN, USA) apparatus. The primary efficacy variable outcomes included rigidity parameters - time to $\geq 60 \%$ rigidity, duration of $\geq 60 \%$ rigidity, maximum rigidity, tumescence activity units (TAUs), and rigidity activity units (RAU) - and responses to the five point Erection Assessment Scale. ${ }^{42}$

Patients' choices for response to the Erection Assessment Scale included "no response", "some enlargement", "full enlargement", "erection sufficient for intercourse", and "rigid erection". Primary safety end points included any AEs, vital sign changes, physical exam findings, and laboratory tests (complete blood count (CBC), chemistry panel, prostate specific antigen (PSA), serum testosterone, prothrombin time, and urine analysis). 
The peak response to avanafil occurred in the early interval (20-40 minutes after dosing) for patients at all doses, while the peak response for sildenafil $50 \mathrm{mg}$ occurred in the middle (60-80 minutes) or late (100-120 minutes) intervals. During the early interval, the avanafil $100 \mathrm{mg}$ and $200 \mathrm{mg}$ treatments were superior to sildenafil $50 \mathrm{mg}$ for duration of $\geq 60 \%$ rigidity; however, sildenafil $50 \mathrm{mg}$ was superior to avanafil during the late interval. The time from beginning of VSS to $\geq 60 \%$ rigidity was significantly shorter with avanafil $100 \mathrm{mg}$ and $200 \mathrm{mg}$ compared to placebo. In comparison, the majority of patients receiving sildenafil $50 \mathrm{mg}$ did not experience reduced time to $\geq 60 \%$ rigidity when compared to placebo. During the early interval, TAU and RAU values were superior with all avanafil treatments compared to placebo. Differences in TAUs between avanafil and placebo therapies were most frequent during the early and middle intervals. During the late interval, only the $200 \mathrm{mg}$ treatment was found to be superior to placebo for TAUs. This supports the aforesaid conclusions that avanafil has quicker onset of action and shorter duration of action. Significant differences for TAUs between sildenafil and placebo were most frequently noted during the middle and late intervals, and sildenafil 50 $\mathrm{mg}$ was superior to avanafil $100 \mathrm{mg}$ during the late interval. This confirms that sildenafil has delayed onset of action, and greater $\mathrm{T}_{\max }$, when compared with avanafil.

All reported AEs for patients receiving avanafil were mild in severity and similar to those observed with other PDE5 inhibitors. The most common AE with avanafil treatment was flushing. This did not seem to be dose-related. Visual impairment was reported in one patient with sildenafil treatment, but there was no visual impairment reported with either avanafil or placebo.

This Phase II study ${ }^{42}$ illustrates avanafil's efficacy and safety for men with mild to moderate ED. Avanafil had rapid onset of action and significantly improved erectile function in response to VSS. During the early interval after dosing, the majority of the efficacy end points for all three avanafil treatment groups were superior to placebo. Compared to sildenafil, which showed greatest efficacy during the late interval, avanafil showed high efficacy earlier after dosing. All doses of avanafil showed some degree of efficacy during the middle interval, and only the $200 \mathrm{mg}$ dose continued to show high efficacy during the late interval. Though avanafil has rapid onset, it appears that the highest dose $(200 \mathrm{mg}$ ) still remains effective in improving erectile function $(\mathrm{EF})$ for longer periods.

\section{Phase III studies}

The first Phase III clinical trial for avanafil assessed its efficacy and safety with 200 men in Korea in a multicenter randomized double-blind placebo-controlled fix-dosed study (Table 4). ${ }^{43}$ All subjects were $>20$ years of age with duration of ED $\geq 6$ months and had made at least four attempts at sexual intercourse, of which at least $50 \%$ were unsuccessful, during the 4-week treatment-free run-in period. Patients with possible confounding health conditions such as cardiovascular disease, endocrine disorders, diabetes mellitus (DM), spinal cord injury, or previous pelvic surgery were excluded from this study. Subjects were randomized to receive one of three treatments for 12 weeks: avanafil $100 \mathrm{mg}$; avanafil $200 \mathrm{mg}$; or placebo. They were instructed to take the medicine 30 minutes before sexual intercourse, but not to exceed one dose per day. The primary efficacy variable was the patient-reported change from baseline in the erectile function domain (EFD) scores on the International Index of Erectile Function (IIEF) questionnaire. ${ }^{44}$ This domain comprises questions one through five and number 15 on the questionnaire. Secondary efficacy variables were based on patient responses to questions two (SEP2) and three (SEP3) from the Sexual Encounter Profile. SEP2 is: "Were you able to insert your penis into your partner's vagina?" SEP3 is: "Did your erection last long enough for you to complete intercourse with ejaculation?" Patient satisfaction after the 12-week treatment period was also assessed with patient responses in other domains of the IIEF (orgasmic function, intercourse satisfaction, sexual desire, and overall satisfaction) and in the Global Assessment Question (GAQ): "Has the treatment you have been taking during the study improved your erections?" AEs were assessed according to seriousness, intensity, and the likely relationship to the study drug. Vital signs, laboratory values, and EKG readings were monitored and recorded for all patients.

Compared to placebo, the patients who received $100 \mathrm{mg}$ or $200 \mathrm{mg}$ of avanafil had a significantly improved IIEF-EFD score. After 12 weeks of on-demand use of avanafil, mean increases from baseline in IIEF-EFD score were 8.5 and 8.8 for the $100 \mathrm{mg}$ and $200 \mathrm{mg}$ groups, respectively. In comparison, the placebo group experienced no statistically significant improvement in IIEF-EFD score (mean increase of 3.5). Furthermore, both avanafil treatment groups showed significant improvements in IIEF-EFD as early as 4 weeks.

Notably, there were no statistically significant differences in IIEF-EFD score between the two avanafil groups. The avanafil treatment groups also showed similar improvements in secondary efficacy measurements - responses to SEP2, SEP3, and GAQ - compared to patients receiving placebo. After 12 weeks of treatment, the proportion of patients achieving normal EFD scores were 16.7\%, 45.6\%, 
and $39.39 \%$ in the placebo, avanafil $100 \mathrm{mg}$, and avanafil $200 \mathrm{mg}$ treatment groups, respectively. In regard to patient satisfaction measurements, both avanafil groups were superior to placebo in the other IIEF domains: orgasmic function; intercourse satisfaction; and overall satisfaction. There was no significant difference between avanafil and placebo in the sexual desire domain. AEs reported with avanafil were similar to those commonly observed with other PDE5 inhibitors. The most frequently reported AEs were flushing (11\% and $13 \%)$ and mild to moderate headache (4\% and $10 \%)$ in patients receiving avanafil $100 \mathrm{mg}$ and $200 \mathrm{mg}$, respectively. There were no reported AEs in objective measurements of vital signs, laboratory values, or EKG readings.

In another Phase III multicenter double-blind placebocontrolled study, 646 men with mild to severe ED were randomized to one of four treatment groups for 12 weeks: avanafil $50 \mathrm{mg}$; avanafil $100 \mathrm{mg}$; avanafil $200 \mathrm{mg}$; or placebo. ${ }^{45}$ The men were stratified within each treatment arm by severity of ED so that, within each group, one third of subjects had mild ED (IIEF-EFD score 17-25), one third had moderate ED (11-16), and one third had severe ED $(\leq 10)$. Subjects were instructed to self-administer the oral treatment medication 30 minutes prior to initiation of sexual activity and were informed that they could take a maximum of 2 doses in a 24-hour period under the stipulation that the doses were spaced $\geq 12$ hours apart. The mean age of subjects was 56 years, and those with diabetes mellitus (DM) and other potential complicating health conditions were excluded. However, patients were not excluded based on prior ED therapy. $72 \%$ of subjects had received previous oral treatment for ED (PDE5 inhibitor or herbals), with $7.5 \%$ of those patients having failed that therapy. The mean duration of ED for the placebo group was 75 months, and for the combined avanafil groups was 79 months. Baseline IIEF-EFD scores were 12.4 and 12.7 for the placebo and avanafil groups, respectively. Primary efficacy outcomes were patient-reported improvement in erectile function based on change from baseline IIEF-EFD score, SEP2, and SEP3. Secondary end points were based on responses for the other domains of the IIEF: orgasmic function; sexual desire; intercourse satisfaction; and overall satisfaction.

After 12 weeks of treatment with avanafil, there were significant improvements in sexual function with all three doses compared to placebo. The mean IIEF-EFD scores increased from 12.6 to $18.1,12.6$ to 20.9 , and 12.8 to 22.2 for the $50 \mathrm{mg}, 100 \mathrm{mg}$, and $200 \mathrm{mg}$ groups, respectively. With regard to SEP2, significant improvement was demonstrated with all doses of avanafil compared to placebo $(P<0.001)$.
Successful vaginal penetration rates (SEP2) increased from $45 \%$ to $64 \%$ for the $50 \mathrm{mg}$ group, from $47 \%$ to $74 \%$ for the $100 \mathrm{mg}$ group, and from $48 \%$ to $77 \%$ for the $200 \mathrm{mg}$ group. With regard to successful intercourse (SEP3), rates increased from $13 \%$ to $41 \%$ for the $50 \mathrm{mg}$ group, from $14 \%$ to $57 \%$ for the $100 \mathrm{mg}$ group, and from $12 \%$ to $57 \%$ for the 200 $\mathrm{mg}$ group. There was no significant change in primary end points for the placebo group. All doses of avanafil increased the percentage of subjects with normalized IIEF-EFD scores ( $\geq 26$ ) more than placebo. Importantly, the $50 \mathrm{mg}$ dose was found to be inferior to the 100 and $200 \mathrm{mg}$ doses in the primary end points. However, there was no appreciable difference between the $100 \mathrm{mg}$ and $200 \mathrm{mg}$ doses, regardless of baseline ED grade. Furthermore, all doses of avanafil produced statistically similar improvements in EF, irrespective of prior ED therapy.

Patients reported significant improvements in three of the four other domains of the IIEF questionnaire with all doses of avanafil. However, patients receiving higher doses (100 $\mathrm{mg}$ and $200 \mathrm{mg}$ ) experienced markedly greater changes than those receiving the lowest dose $(50 \mathrm{mg})$. Improvements in the sexual desire domain were minimal in all avanafil treatment groups. This study also evaluated the timing of successful intercourse attempts (SEP3) following drug administration. With all three doses, patients reported substantial improvements in percentage of successful sexual attempts within 15 minutes of administration. Patients receiving avanafil $50 \mathrm{mg}$, avanafil $100 \mathrm{mg}$, and avanafil $200 \mathrm{mg}$ were successful in $64 \%, 67 \%$, and $71 \%$ of sexual attempts within 15 minutes of dosing, compared to $27 \%$ for patients receiving placebo. This is consistent with avanafil's pharmacokinetic profile, which includes a rapid onset of action.

Avanafil treatment was well tolerated; $37.9 \%$ of patients receiving avanafil and $26.1 \%$ of patients receiving placebo reported AEs. The most frequently reported AEs included headache, flushing, nasal congestion, nasopharyngitis, and back pain. Hemodynamic AEs (dizziness and syncope) occurred in $<2 \%$ of patients receiving avanafil. Discontinuation rates due to AEs were low among all groups, ranging from $1.9 \%$ to $3.1 \%$.

In this Phase III clinical trial, ${ }^{45}$ on-demand avanafil showed efficacy for improving EF in patients with uncomplicated ED. Similar to other studies, avanafil showed a fast onset of action, with treatment responses as early as 15 minutes, and effects reported beyond 6 hours in some patients. The infrequency of AEs supports avanafil's favorable pharmacodynamic properties. 


\section{Phase III studies in difficult-to-treat populations}

A Phase III multicenter randomized double-blind placebocontrolled study investigated the efficacy of avanafil for treatment of men with ED and concurrent DM. ${ }^{46}$ The prevalence of ED in men with DM has been reported to be as high as $71 \%$. In this study, 390 men aged 18 years or older with documented type 1 or $2 \mathrm{DM}$ and $\geq 6$ months' history of mild to severe ED were randomized to receive treatment for 12 weeks, which included avanafil $100 \mathrm{mg}$, avanafil $200 \mathrm{mg}$, or placebo. The study was limited to men with controlled DM; those with glycated hemoglobin $>9 \%$ were excluded. Ninety percent of subjects had type $2 \mathrm{DM}$ and most presented with moderate to severe ED (78\%). Additionally, the majority of patients had other comorbidities such as dyslipidemia and hypertension, and were actively taking medications for these conditions. Previous use of oral ED therapy was reported in $75 \%$ of the study population.

Subjects were instructed to take the drug 30 minutes before initiation of sexual activity and were allowed up to two doses per day, but subsequent doses had to be separated by $\geq 12$ hours. Efficacy was assessed by three primary end points: change in response to SEP3; change in response to SEP2; and change in IIEF-EFD score. Secondary efficacy variables included change in response to individual diary questions and other components of the IIEF between baseline and the end of treatment. Safety was monitored by reported AEs and vital signs at each visit. Additionally, EKG, laboratory values, and physical examination results were evaluated at screening and at the final visit.

Compared to placebo, mean change from baseline in IIEF-EFD, SEP2, and SEP3, were significantly improved with both avanafil treatments. Mean increases in IIEF-ED score of the avanafil $100 \mathrm{mg}$ group and avanafil $200 \mathrm{mg}$ group were 4.5 and 5.4, respectively, compared to 1.8 for the placebo group. Percentage of attempts with successful vaginal penetration was increased by $21.5 \%$ and $25.9 \%$ for avanafil $100 \mathrm{mg}$ and avanafil $200 \mathrm{mg}$, respectively. The placebo group only experienced a $7.5 \%$ increase in this end point. With regard to SEP3, avanafil improved the ability of men with ED to maintain an erection of sufficient duration for successful intercourse. The improvements in successful sexual attempts were $13.6 \%, 28.7 \%$, and $34.0 \%$ for placebo, avanafil $100 \mathrm{mg}$, and avanafil $200 \mathrm{mg}$, respectively. There were no appreciable differences in primary end points between the two avanafil dosage groups. It is also notable that avanafil's benefit was consistent across all subjects regardless of type of DM, DM duration, baseline ED severity, and duration of ED.
Secondary end points were also improved by treatment with avanafil. Specifically, patients reported enhanced orgasmic function, intercourse satisfaction, and overall satisfaction after the treatment period, using the IIEF questionnaire. Patient responses to diary questions about satisfaction with sexual experience are consistent with the improved IIEF domain scores. Similar to other studies, there was no notable change in sexual desire after treatment. With regard to the duration of action of avanafil, patients receiving avanafil reported significant increase in percentage of successful sexual attempts (SEP3) from $<15$ minutes after dosing to $>6$ hours after dosing. For attempts initiated $<15$ minutes after administration, $62.3 \%$ and $35.6 \%$ were successful in men receiving avanafil 100 and $200 \mathrm{mg}$, respectively, compared to $26.1 \%$ for placebo-treated men. For attempts initiated $>6$ hours after dosing, $50 \%$ and $67.7 \%$ were successful after treatment with avanafil 100 and $200 \mathrm{mg}$, respectively, compared to $4.8 \%$ for the placebo group. Though avanafil has been promoted for its rapid absorption and onset, it also maintains positive effects on EF 6 hours after administration.

Drug-related AEs were reported in $23.8 \%, 35.4 \%$, and $32.1 \%$ of patients receiving placebo, avanafil $100 \mathrm{mg}$, and avanafil $200 \mathrm{mg}$, respectively. All drug-related AEs were mild or moderate - most commonly headache, nasopharyngitis, flushing, and back pain. Vision changes were reported in one patient overall; he was taking avanafil $200 \mathrm{mg}$. There were no significant drug-related changes in vital signs, laboratory values, or physical examination results, and there were no reported drug-drug interactions with antidiabetic medications. These data support avanafil's selectivity for the PDE5 enzyme as determined by in vitro studies. Further, it appears safe to administer to diabetic patients as well as patients on blood-pressure lowering medications, including alphablockers (sample size of 24 patients).

The efficacy and safety of avanafil in a different difficultto-treat population - men with prior pelvic surgery - was evaluated in a Phase III clinical trial. ${ }^{47}$ This randomized double-blind placebo-controlled parallel group study included males aged 18-70 years with a history of ED of 6 months or more after bilateral nerve sparing radical prostatectomy. Patients who had undergone chemotherapy, radiation, androgen-deprivation therapy, or penile-rehabilitation treatment were excluded from this study. Administration of medications for hypertension was permitted, including the use of alpha-blockers. A total of 298 patients were randomized to receive avanafil $100 \mathrm{mg}$, avanafil $200 \mathrm{mg}$, or placebo for 12 weeks. The drug was to be taken approximately 30 minutes before initiation of sexual activity. Patients were restricted 
to a maximum of two doses per 24-hour period. At baseline, $71.5 \%$ of patients had severe ED, with a mean overall IIEFEFD score of 9.2. The mean SEP3 sexual-attempt success rate at baseline was $<5 \%$. Primary end points of the study were change in SEP2, SEP3, and IIEF-EFD from baseline to the end of treatment. Secondary end points included the remaining domains of the IIEF questionnaire, responses to subject diary questions and GAQ on treatment effect, and future use of the study drug.

Following 12 weeks of treatment with avanafil, there was a significantly greater increase in SEP2, SEP3, and change in mean IIEF-EFD compared to placebo $(P<0.01)$. At the end of treatment, SEP 2 rates increased from $17 \%$ to $32 \%$ and $20 \%$ to $41 \%$ with the $100 \mathrm{mg}$ and $200 \mathrm{mg}$ doses, respectively. There was no change for the placebo group. SEP3 rates increased from $5 \%$ to $23 \%, 5 \%$ to $26 \%$, and $4 \%$ to $9 \%$ for avanafil $100 \mathrm{mg}$, avanafil $200 \mathrm{mg}$, and placebo, respectively. With regard to IIEF-EFD scores, patients in the $100 \mathrm{mg}$ avanafil group had an improvement of 3.6 (40\% change) and patients in the $200 \mathrm{mg}$ group had an improvement of 5.2 (55\% change), compared with 0.1 ( $1 \%$ change) for placebo. Both doses of avanafil produced significant improvements in EF regardless of baseline ED severity or patient age. However, only the avanafil $200 \mathrm{mg}$ group demonstrated improvement in all three primary end points irrespective of the surgical approach (open, laparoscopic, or robotic).

Secondary end points all showed increased patient satisfaction with avanafil over placebo. Subject diary responses identified that patients receiving avanafil were more satisfied with their erection and experienced an enhanced sexual experience. Of the avanafil $100 \mathrm{mg}$ and avanafil $200 \mathrm{mg}$ groups, $31.3 \%$ and $41.3 \%$ of patients responded that the treatment improved their erections (GAQ). Treatment with avanafil $200 \mathrm{mg}$ generated a much more positive response to the future use question about using the study drug if it were available today (57.6\%), compared to avanafil $100 \mathrm{mg}$ (39.8\%), and placebo $(27.7 \%)$. This study also evaluated the duration of action of avanafil. Patients who received avanafil $100 \mathrm{mg}$ reported significant improvement in SEP2 and SEP3 in all time intervals measured (from $\leq 15$ minutes through $>6$ hours after dosing). The $200 \mathrm{mg}$ avanafil group only experienced marked improvement in SEP2 and SEP3, compared to placebo, until 4 hours post-administration. Similar to other studies, there was a statistically significant improvement in successful sexual attempts (SEP3) for both doses of avanafil within $\leq 15$ minutes in the interval after dosing.

Avanafil was tolerated well, with only $2 \%$ of patients discontinuing from the study due to AEs. No severe AEs were reported. The most common AEs were headache (7.0\%), flushing (5.0\%), and nasopharyngitis $(2.7 \%)$, and the severity of these AEs appeared to be dose-dependent. Hemodynamic AEs occurred in less than $2 \%$ of patients. This study demonstrates that patients with post-radical prostatectomy ED can benefit from treatment with avanafil, though this response may be reduced compared to that in the rest of the population.

\section{Phase III studies evaluating long-term use of avanafil}

In order to determine the long-term efficacy, safety, and tolerability of avanafil, a 52-week, open label extension of two of the previous 12-week Phase III trials was conducted. ${ }^{45,46}$ Patients from Research Evaluating an Investigational Medication for Erectile Dysfunction (REVIVE) TA-301 (DM excluded study) and TA-302 (exclusively patients with DM) were included in this continuation study. ${ }^{48}$ All patients in the extension trial were assigned to treatment with avanafil 100 mg. Patients were allowed, upon request, to either increase their dose to $200 \mathrm{mg}$ for increased efficacy or decrease their dose to $50 \mathrm{mg}$ for increased tolerability. Again, patients were told to take one dose of the drug approximately 30 minutes before sexual activity, with a maximum of two doses in any 24-hour period. A total of 712 patients were initially enrolled with a mean age of 56.4 years. The mean duration of ED was greater than 5 years. Approximately $32 \%$ of the patients had concomitant DM. A total of 171 patients remained on avanafil $100 \mathrm{mg}$ for the entire study (100 mg group), while 536 requested their dose be increased to $200 \mathrm{mg}$ ( $100 \mathrm{mg} / 200 \mathrm{mg}$ group) and only three patients requested a decreased dose (100 mg/50 $\mathrm{mg}$ group). In total, 492 patients completed the extended trial. Primary end points of the study were change in SEP2, SEP3, and IIEFEFD from baseline to the end of treatment.

Avanafil treatment was associated with SEP2 improvements from $44.1 \%$ at baseline to $83.3 \%$ for the $100 \mathrm{mg}$ group and from $43.0 \%$ to $79.4 \%$ for the $100 \mathrm{mg} / 200 \mathrm{mg}$ group. SEP3 rates increased from $13.3 \%$ to $67.7 \%$ in the $100 \mathrm{mg}$ group and from $11.4 \%$ to $66.3 \%$ in the $100 \mathrm{mg} / 200 \mathrm{mg}$ group. The mean IIEF-EFD score improved from 13.6 to 22.2 and from 11.9 to 22.7 for the $100 \mathrm{mg}$ and $100 \mathrm{mg} / 200 \mathrm{mg}$ groups, respectively. AEs were similar to those reported in other clinical trials. A 30.9\% discontinuation rate was noted, however only $2.8 \%$ were due to AEs. As with previous trials, avanafil showed rapid onset of action and an effect lasting beyond 6 hours of dosing. Overall, $75 \%$ of patients requested an increase in avanafil dosage from $100 \mathrm{mg}$ to $200 \mathrm{mg}$. These 
patients reported an additional improvement in erectile function with this change. Of those patients who did not respond initially to the $100 \mathrm{mg}$ dose, $65 \%$ went on to respond to the increased dose.

\section{Conclusion}

Since the introduction of sildenafil in 1998, PDE5 inhibitors have demonstrated a remarkable efficacy in treating ED. Avanafil is a novel US Food and Drug Administrationapproved second-generation PDE5 inhibitor that offers a favorable pharmacodynamic and pharmacokinetic profile in comparison to current PDE5 inhibitors. Studies of avanafil have shown superior selectivity for the PDE5 isoenzyme and fewer interactions with other PDE isoenzymes, hence exhibiting fewer side effects and drug-drug interactions. Notably, avanafil has fewer hemodynamic side effects and appears safe to use in patients on blood-pressure lowering medications. As a significant group of patients with ED have concomitant cardiovascular conditions, this quality may make second-generation PDE5 inhibitors with minimal effects on blood pressure a tolerable treatment for many patients.

Avanafil has a rapid onset and shorter duration of action than current PDE5 inhibitors. It reaches maximal plasma levels in less than 30 minutes and improves $\mathrm{EF}$ in less than 15 minutes after dosing. Avanafil remains effective for 6 hours and may maintain benefits longer in some patients. Its brief plasma halflife (3-5 hours) reduces the risk of drug-drug interactions - an important property in a patient population that is often taking medications for other health related conditions.

Most importantly, avanafil has demonstrated comparable efficacy to the current oral PDE5 inhibitor options: sildenafil, vardenafil, and tadalafil. Patients have consistently been satisfied with the effects of avanafil on their sexual lives, including those who had previously tried and failed other ED therapies. Avanafil's benefits also apply to patients with comorbidities such as those with concurrent DM or prior pelvic surgery.

\section{Disclosure}

Dr Wayne Hellstrom is a clinical trial investigator and advisory board member for Vivus, Inc. and Auxilium Pharmaceuticals, Inc. The authors report no other conflicts of interest in this work.

\section{References}

1. Montague DK, Jarow JP, Broderick GA, et al. Chapter 1: The management of erectile dysfunction: an AUA update. J Urol. 2005;174(1):230-239.

2. Latini DM, Penson DF, Wallace KL, Lubeck DP, Lue TF. Clinical and psychosocial characteristics of men with erectile dysfunction: baseline data from ExCEED. J Sex Med. 2006;3(6):1059-1067.
3. Litwin MS, Nied RJ, Dhanani N. Health-related quality of life in men with erectile dysfunction. J Gen Intern Med. 1998;13(3):159-166.

4. Ayta IA, McKinlay JB, Krane RJ. The likely worldwide increase in erectile dysfunction between 1995 and 2025 and some possible policy consequences. BJU Int. 1999;84(1):50-56.

5. Selvin E, Burnett AL, Platz EA. Prevalence and risk factors for erectile dysfunction in the US. Am J Med. 2007;120(2):151-157.

6. Kalsi JS, Kell PD. Update on oral treatments for male erectile dysfunction. J Eur Acad Dermatol Venereol. 2004;18(3):267-274.

7. Wespes E, Amar E, Hatzichristou D, et al. EAU Guidelines on erectile dysfunction: an update. Eur Urol. 2006;49(5):806-815.

8. Doggrell SA. Comparison of clinical trials with sildenafil, vardenafil and tadalafil in erectile dysfunction. Expert Opin Pharmacother. 2005;6(1):75-84.

9. Dean RC, Lue TF. Physiology of penile erection and pathophysiology of erectile dysfunction. Urol Clin North Am. 2005;32(4):379-395, v.

10. Kedia GT, Uckert S, Assadi-Pour F, Kuczyk MA, Albrecht K. Avanafil for the treatment of erectile dysfunction: initial data and clinical key properties. Ther Adv Urol. 2013;5(1):35-41.

11. Limin M, Johnsen N, Hellstrom WJ. Avanafil, a new rapid-onset phosphodiesterase 5 inhibitor for the treatment of erectile dysfunction. Expert Opin Investig Drugs. 2010;19(11):1427-1437.

12. Yuan J, Zhang R, Yang Z, et al. Comparative effectiveness and safety of oral phosphodiesterase type 5 inhibitors for erectile dysfunction: a systematic review and network meta-analysis. Eur Urol. 2013;63(5): 902-912.

13. Bruzziches R, Francomano D, Gareri P, Lenzi A, Aversa A. An update on pharmacological treatment of erectile dysfunction with phosphodiesterase type 5 inhibitors. Expert Opin Pharmacother. 2013;14(10): 1333-1344.

14. Kang SG, Kim JJ. Udenafil: efficacy and tolerability in the management of erectile dysfunction. Ther Adv Urol. 2013;5(2):101-110.

15. Bell AS, Palmer MJ. Novel phosphodiesterase type 5 modulators: a patent survey (2008-2010). Expert Opin Ther Pat. 2011;21(10): 1631-1641.

16. FDA approves Stendra for erectile dysfunction (webpage on the Internet). Silver Spring: US Food and Drug Administration; 2012. Available from: http://www.fda.gov/newsevents/newsroom/ pressannouncements/ucm302140.htm. Accessed February 23, 2014.

17. Burke RM, Evans JD. Avanafil for treatment of erectile dysfunction: review of its potential. Vasc Health Risk Manag. 2012;8:517-523.

18. Allison M, Grant T, Obaidi M, Marenco T, Yee S, Day W. Pharmacokinetics of avanafil; a novel, rapidly absorbed, selective PDE5 inhibitor for the treatment of mild to severe erectile dysfunction. J Sex Med. 2011(8):S466-S467.

19. Viagra [package insert]. New York, NY: Pfizer Labs; 2010.

20. Levitra [package insert]. Wayne, NJ: Bayer HealthCare Pharmaceuticals; 2011.

21. Cialis [package insert]. Indianapolis, IN: Eli Lilly and Company; 2011.

22. Stendra [package insert]. Mountain View, CA: Vivus; 2013.

23. Fabbri A, Aversa A, Isidori A. Sildenafil and erectile dysfunction. J Endocrinol Invest. 1999;22(6):486-492.

24. Bischoff E. Vardenafil preclinical trial data: potency, pharmacodynamics, pharmacokinetics, and adverse events. Int J Impot Res. 2004; 16 Suppl 1:S34-S37.

25. Forgue ST, Patterson BE, Bedding AW, et al. Tadalafil pharmacokinetics in healthy subjects. Br J Clin Pharmacol. 2006;61(3):280-288.

26. Gingell C, Sultana SR, Wulff MB, Gepi-Attee S. Duration of action of sildenafil citrate in men with erectile dysfunction. J Sex Med. 2004;1(2): 179-184.

27. Gupta M, Kovar A, Meibohm B. The clinical pharmacokinetics of phosphodiesterase-5 inhibitors for erectile dysfunction. $J$ Clin Pharmacol. 2005;45(9):987-1003.

28. Hatzimouratidis K, Amar E, Eardley I, et al. Guidelines on male sexual dysfunction: erectile dysfunction and premature ejaculation. Eur Urol. 2010;57(5):804-814. 
29. Carrier S. Pharmacology of phosphodiesterase 5 inhibitors. Can J Urol. 2003;10 Suppl 1:12-16.

30. Seftel AD. Phosphodiesterase type 5 inhibitors: molecular pharmacology and interactions with other phosphodiesterases. Curr Pharm Des. 2005;11(31):4047-4058.

31. Wang R, Burnett AL, Heller WH, et al. Selectivity of avanafil, a PDE5 inhibitor for the treatment of erectile dysfunction: implications for clinical safety and improved tolerability. J Sex Med. 2012;9(8):2122-2129.

32. Laties A, Sharlip I. Ocular safety in patients using sildenafil citrate therapy for erectile dysfunction. J Sex Med. 2006;3(1):12-27.

33. Laties A, Zrenner E. Viagra (sildenafil citrate) and ophthalmology. Prog Retin Eye Res. 2002;21(5):485-506.

34. Laties AM. Vision disorders and phosphodiesterase type 5 inhibitors: a review of the evidence to date. Drug Saf. 2009;32(1):1-18.

35. Kotera J, Mochida H, Inoue H, et al. Avanafil, a potent and highly selective phosphodiesterase-5 inhibitor for erectile dysfunction. J Urol. 2012;188(2):668-674.

36. Mochida H, Yano K, Inoue H, Yee S, Noto T, Kikkawa K. Avanafil, a highly selective phosphodiesterase type 5 inhibitor for erectile dysfunction, shows good safety profiles for retinal function and hemodynamics in anesthetized dogs. J Urol. 2013;190(2):799-806.

37. Vlachopoulos C, Ioakeimidis N, Rokkas K, Stefanadis C. Cardiovascular effects of phosphodiesterase type 5 inhibitors. $J$ Sex Med. 2009;6(3):658-674.

38. Hellstrom WJ, Overstreet JW, Yu A, et al. Tadalafil has no detrimental effect on human spermatogenesis or reproductive hormones. J Urol. 2003;170(3):887-891.

39. Yilmaz D, Bayatli N, Un O, Kadowitz PJ, Sikka SC, Gur S. The effect of intracavernosal avanafil, a newer phosphodiesterase-5 inhibitor, on neonatal type 2 diabetic rats with erectile dysfunction. Urology. 2014;83(2):508. e7-e12.

40. Jung J, Choi S, Cho SH, et al. Tolerability and pharmacokinetics of avanafil, a phosphodiesterase type 5 inhibitor: a single- and multipledose, double-blind, randomized, placebo-controlled, dose-escalation study in healthy Korean male volunteers. Clin Ther. 2010;32(6): $1178-1187$.
41. Swearingen D, Nehra A, Morelos S, Peterson CA. Hemodynamic effect of avanafil and glyceryl trinitrate coadministration. Drugs Context. 2013;2013:212248.

42. Hellstrom WJ, Freier MT, Serefoglu EC, Lewis RW, DiDonato K, Peterson CA. A phase II, single-blind, randomized, crossover evaluation of the safety and efficacy of avanafil using visual sexual stimulation in patients with mild to moderate erectile dysfunction. BJU Int. 2013;111(1):137-147.

43. Zhao C, Kim SW, Yang DY, et al. Efficacy and safety of avanafil for treating erectile dysfunction: results of a multicentre, randomized, doubleblind, placebo-controlled trial. BJU Int. 2012;110(11):1801-1806.

44. Rosen RC, Riley A, Wagner G, Osterloh IH, Kirkpatrick J, Mishra A. The international index of erectile function (IIEF): a multidimensional scale for assessment of erectile dysfunction. Urology. 1997;49:822

45. Goldstein I, McCullough AR, Jones LA, et al. A randomized, doubleblind, placebo-controlled evaluation of the safety and efficacy of avanafil in subjects with erectile dysfunction. J Sex Med. 2012;9(4): 1122-1133.

46. Goldstein I, Jones LA, Belkoff LH, et al. Avanafil for the treatment of erectile dysfunction: a multicenter, randomized, double-blind study in men with diabetes mellitus. Mayo Clinic Proc. 2012;87(9):843-852.

47. Mulhall JP, Burnett AL, Wang R, et al. A phase 3, placebo controlled study of the safety and efficacy of avanafil for the treatment of erectile dysfunction after nerve sparing radical prostatectomy. J Urol. 2013;189(6):2229-2236.

48. Belkoff LH, McCullough A, Goldstein I, et al. An open-label, longterm evaluation of the safety, efficacy and tolerability of avanafil in male patients with mild to severe erectile dysfunction. Int J Clin Pract. 2013;67(4):333-341.
Therapeutics and Clinical Risk Management

\section{Publish your work in this journal}

Therapeutics and Clinical Risk Management is an international, peerreviewed journal of clinical therapeutics and risk management, focusing on concise rapid reporting of clinical studies in all therapeutic areas, outcomes, safety, and programs for the effective, safe, and sustained use of medicines. This journal is indexed on PubMed Central, CAS,

\section{Dovepress}

EMBase, Scopus and the Elsevier Bibliographic databases. The manuscript management system is completely online and includes a very quick and fair peer-review system, which is all easy to use. Visit http://www.dovepress.com/testimonials.php to read real quotes from published authors. 